\title{
The Role of Zone of Proximal Development in the Students' Learning of English Adverbs
}

\author{
Abbas Ali Rezaee \\ Faculty of Foreign Languages and Literatures, University of Tehran, Iran \\ Email: aarezaee@ut.ac.ir \\ Zeinab Azizi \\ Faculty of Foreign Languages and Literatures, University of Tehran, Iran \\ Email: luna@yahoo.com
}

\begin{abstract}
The Zone of Proximal Development (ZPD) first articulated by the Soviet psychologist Lev Vygotsky. It is the difference between what a learner can do without receiving any help and what he can do after receiving help. Not much research has been conducted in the role of ZPD and the students' learning of learning English grammar. This study attempts to investigate ZPD in the realm of teaching English adverbs. For this purpose, 86 students studying in grade one of high school were selected. They were randomly divided into three groups, i.e., a control group, a ZPD error correction experimental group and a non-ZPD error correction experimental group. During a four-week period, certain units from Book One of High School, in which English adverbs had been covered, were taught. The first test was administered to see the possible differences between ZPD and non-ZPD groups. Then, after six weeks, the second test was used to investigate whether teaching within the frameworks of ZPD leads to better long-term retention. It was found that students learn better and deeper if they are taught English adverbs, within their ZPD. Learning is significantly enhanced when the class atmosphere is in a cooperative and supportive mood.
\end{abstract}

Index Terms - The Zone of Proximal Development (ZPD), cooperative learning, corrective feedback, English adverbs, scaffolding, error correction

\section{INTRODUCTION}

The idea of the Zone of Proximal Development (ZPD) was first articulated in the 1930's by the Soviet psychologist Lev Vygotsky. (Beheshti, Bowler, Large \& Nesset, 2000) Vygotsky's notion of the ZPD, being the gap between learners' current of actual development level determined by independent problem-solving and the learners' emerging or potential level of development, was suppressed until 1958. It, found its way back to the research community in the late 1970's. However, Schutz (2004) holds that although Vygotsky's ideas were lying dormant for so many years, his "theories of cognitive development have had a profound effect on education in Russia, as well as the United States and Canada, helping to shape theories of teaching and learning in each country" (p. 13).

Within the last three to four decades many research studies have been conducted in different areas of learning while taking into account Vygotsky's notions. However, there are stills rooms for investigating the degree the ZPD can affect learning different language components and skills. It has become clear that many students face problems in grasping the true sense of adverbs and using them in well-structures sentences. What has been taken as the main concern in the present research is to see whether teaching within the frameworks of the ZPD can enhance students' learning of English adverbs and whether it can benefit them to use adverbs with more accuracy and confidence.

\section{REVIEW OF THE LITERATURE}

\section{A. Zone of Proximal Development}

The ZPD is the gap between what a learner has already mastered, his actual level of development, and what he can achieve when provided with educational support, called potential development. The ZPD is believed to point out the difference between the child's capacity to solve problems on his own, and his capacity to solve them along with receiving assistance (Schutz, 2004). In fact, all the tasks that a child is able to do alone can be referred to as developmental level. On the other hand, ZPD comprises scaffolding process which is performing the activities with the help of teacher, a parent, caretaker, language instructor or another peer who has already mastered that particular function. The notion of the ZPD clearly reflects Vygotsky's view on the nature of human development and interrelation between learning and development. Learning, which is distinct from development, may lead to development and ZPD is the abstraction that describes the mechanism and potential effect of learning on development.

So in scaffolding process peers or teachers' help is necessary for a child's development within the ZPD. It is possible to describe another kind of teaching and the way of helping teacher in this process by human sciences of the last half 
century. Wertsch and Stone (1985) believe that research on teaching has been galvanized in the past few years by some seminal concepts from recently translated works of Vygotsky. His thoughts affect our understanding of learning and teaching. Vygotsky's insights have also affected our understanding of teaching. In his theory, what a learner can learn without the help of others can be considered as developmental level. Assisted versus unassisted performance is distinguishing point so that teaching must be redefined as assisted performance and teaching occurs when performance is achieved with assistance through a child's ZPD.

As stated above, it is clear that ZPD emphasizes the distance between what a learner can learn by him/herself and what he/she can learn by assistance of teachers or peers. In this regards, two main concepts, i.e., problem solving and corrective feedback which have essential roles need to be elaborated. Scott (2008) supposes that corrective feedback helps learners in retrieval of the target language form rather than providing the correct form. He holds that:

Language learners will benefit from corrective feedback that makes them retrieve the target language form (rather than immediately supplying the correct form). The retrieval and subsequent production stimulates the development of connections in the learner's memory. Error feedback can be effective, but it must be sustained over a period of time, and it must be focused on something which learners are actually capable of learning. Instruction then draws learner's attention to language features and permits them to develop knowledge of those features if they are developmentally ready to do so. The rate a teacher has to give corrective feedback to her students is usually a good indication of what current stage of interlanguage the students are on. (p. 35).

\section{B. Cooperative Learning}

Among the popular approaches towards learning language components are those which manifest learning by collaboration and interaction. As Dillenbourg (1999) discussed, collaborative learning is not one single mechanism. In fact learners perform the tasks and activities since they produce specific learning processes not because they are two. One of the most important methods of learning is Cooperative Language Learning (CLL) that is considered as a part of Collaborative Learning (CLL) which is an instructional approach. Olsen and Kagan (as cited in Richards \& Rodgers, 2001) believe that:

Cooperative Learning is an approach to teaching that makes maximum use of cooperative activities involving pairs and small groups of learners in the classroom. Cooperative learning is group learning activity organized so that learning is dependent on the socially structured exchange of information between learners in groups and in which each learner is held accountable for his or her own learning and is motivated to increase the learning of others. (p. 192)

Because in the realm of collaborative situation learners and teacher interact with each other, it can be said that a kind of social interaction is performed. Dillenbourg (1999) emphasizes that 'collaborative learning' describes a situation in which particular forms of interaction among people are expected to occur, which would trigger learning mechanisms, but there is no guarantee that the expected interactions will actually occur. In this way, creating a chance to develop different kinds of interactions can help peers to perform the tasks. Concerning the profits of collaborative learning and effects of group working in the learning context, Widdowson (1990) asserts that cooperative learning is one of the best researched of all teaching strategies. There are some definite methods which show that teachers and students are more successful in groups because they have the opportunities of collaborative work in which the students can learn better and faster and also they can feel that they are an important member in the group that help develop the processes of learning and teaching. So, when they have a positive view towards the learning process, they will learn more efficiently. Of course it is not true that just making a group and assigning a project that learners should do can necessarily end in success. Nevertheless, the teacher should be aware of the essential methods of cooperative learning and social interactions among the peers.

Cooperative learning is a general term for different small group interactive instructional processes. Students work together on academic tasks in small groups to help themselves and their partners learn together. Students are responsible for their learning and they perform the task of learning as if they need each other. So the learners can learn better and deeper in groups with positive interactions than doing the tasks alone. In this regard Gokhale (1995) emphasizes that:

The term 'collaborative learning' refers to an instruction method in which students at various performance levels work together in small groups toward common goals. The students are responsible for one another's learning as well as their own. Thus, the success of one student helps other students to be successful. (p. 4)

Collaborations between teacher and students and among students comprise the classroom interaction in which students work together in small groups to learn and they are responsible for their learning. These methods emphasize the use of team goals and team success which can be achieved only if all members of the team learn the objectives being taught. Mayer (2003) declares that in order to teach, begin with a familiar, concrete example or analogy and help students relate the information to personal experiences, then explicitly state how and why material will be useful and use personalized speech. Helping students feel confident that they can master the material can be the next important item affecting on motivation development. As a matter of fact, tasks are not something to do together as a team but to learn together as a team. Collaborative learning happens when students work in pairs or groups. Students and teachers negotiate the rules that govern them. They discuss what are to be taught and how they should be taught. Descriptions of classroom interaction focused initially on the language used by the teacher, especially teacher questions and the learner responses. An important feature is how a teacher can create the interaction opportunities in learning context. 
Fortenberry (1998) considers that collaborative learning skills are designed to maximize four attributes among students, which are 'positive interdependence', 'individual accountability', 'equal participation', and 'simultaneous interaction'.

In traditional models of classroom learning there used to be no or very little cooperative interaction among the learners themselves on the one hand and between the teacher and the students on the other. In fact, in that teacherfronted model competition was more fostered than cooperation. It is now held that there are advantages in learnercentered approach over teacher-fronted methods. According to Brown (2001), there are certain characteristics shared in approximately all cooperative learning methods:

- Students work together on the tasks which are better done in group work.

- Two to five members should be in every small group.

- Students use cooperative, pro-social behavior to accomplish their ordinary tasks or learning activities.

- Students are positively interdependent.

- Activities are structured in a way that students need each other to complete their common tasks or learning activities.

- Students are individually accountable or responsible for their work or learning.

In second language teaching, Cooperative Language Learning has been embraced as a way of promoting communicative interaction in the classroom and is seen as an extension of the principles of Communicative Language Teaching. Learner-centered approach has more advantages over a teacher-centered because it helps improve learner's motivation and decrease his stress of performing the task alone, and also it provides the opportunity for communication strategies, social interactions and doing interactive tasks. Accordingly, through interactive group activities a variety of curricula can be applied.

\section{Corrective Feedback}

Celce-Murcia (1991) holds that "The history of second language teaching has witnessed changing perceptions of corrective feedback" (p. 244). Moreover, Gass (1997, p. 34) believes that views on the role of corrective feedback can be highly diverse, even polarized. The Audiolingual method of language teaching, for example, advocated minimal or no tolerance of learner errors It suggested that every effort should be made to prevent errors. On the other hand, the Natural Approach considered error correction unnecessary and counterproductive. The latter view is also shared notably by the Communicative Language Teaching (CLT) approach that has come to dominate L2 classrooms since the early 1970s.

Regarding deep changes of researchers' attitudes toward corrective feedback for a long time, it is necessary to have some pieces of information about the principles of corrective feedback and its meaning. Gass (1997) affirms that corrective feedback is referred to as any behavior of supplying an appropriate item in response to what is perceived and interpreted to be an error committed by students .It seems to be a current tendency that many teachers and researchers treat producing incorrect forms as a positive phenomenon in which learners are trying to form and test their interlanguage systems. In this respect, whatever reactions teachers will make to learners' errors are considered a crucial aspect of language teaching, recognizing that making errors is the representative of the learning processes.

Corrective feedback is categorized into two different branches, explicit corrective feedback and implicit one. Gass (1997) disagrees with some researchers who believe that experienced teachers use more implicit corrective feedback than explicit corrective feedback, because explicit corrective feedback breaks the main sequence of communication. It is expected that this feedback occurs less frequently than implicit corrective feedback. Teachers should keep in mind a good balance between explicit feedback and implicit feedback. Explicit feedback tends to push the students forward to alter the interim grammar and implicit feedback is likely to let the communication flow smoothly. Experienced teachers allow their students to self-correct more often than other-correct and they react to errors with much more explicit corrective feedback than implicit feedback. As to feedbacks provided by teachers or supervisors Scheeler, Ruhl, and MacAfee (2004) hold that teachers should insist on receiving feedback for improving the new teaching methods they might try to apply in their classrooms. They also talk about the different forms feedbacks may take.

Teachers who attempt to try new teaching methods must receive regular feedback about the impact of new practices on student learning. In order to provide effective feedback to teachers, supervisors and others involved in teacher preparation must first know the attributes of effective feedback. However, feedback may take many forms, may be delivered in many ways at different parts of the learning process, and by different individuals. The nature of the behavior that is the focus of the feedback may also impact feedback effectiveness. (p. 31)

Some of the researchers concern the error in learning context as a precious matter by which students are helped to learn the points more carefully and learning in this kind of process hardly will be forgotten. Negative feedback is essential to L2 learners when positive input is inadequate to lead the learners towards the correct form of the target language. Due to the incompleteness of relevant data available to L2 learners, such learners need to be provided with feedback. Feedback can help the L2 learners learn the subject matters deeply. The usefulness of corrective feedback is highly dependent upon the nature of the transaction and mediation provided by the expert in this procedure. Nassaji and Swain (1997) suppose that within the Vygotskian sociocultural perspective and drawing the Vygotskian notion of the ZPD, corrective feedback can result in better and deeper learning. Error correction is considered as a social activity involving joint participation and meaningful transaction between the learners and the teachers. 
One aspect of ZPD in language acquisition is the role of corrective feedback. There seems to be a general consensus among researchers that corrective feedback has a role to play in second language (L2) learning. Nassaji and Swain (1997) find out that negotiated help provided within the learners' ZPD is more effective than help provided randomly. A difference between ZPD and non-ZPD students' performance is revealed in a way that ZPD students outperformed nonZPD students in the final task. Furthermore, ZPD students exhibited consistent growth over time, a pattern not observed in non-ZPD student's performance. This lack of consistency can be interpreted in light of the nature of the random help and the mismatch between the random help and the level of feedback the learner needed. So more learning took place in the case of ZPD learner versus non-ZPD learner. Several cases of intra-session (micro genetic) and inter-session (macro genetic) growth were observed among ZPD students. Such learning indicators are not observed in non-ZPD students. Much of the time, the random prompts failed to help non-ZPD students. These findings are consistent with the Vygotskian sociocultural perspective in which knowledge is defined as social in nature and are constructed through a process of collaboration, interaction, and communication among learners in social settings and as the result of interaction within ZPD.

Finally, it should be noted that the direction in ZPD classes is neither a bottom up process nor a top down one, but activities are directed in double-move processes. This means that sometimes a general rule was considered first; then the details were discussed and at other times the detailed and minor subjects took the priority (Lantolf \& Throne, 2006).

\section{THE PRESENT STUDY}

The researchers intend to find a new trace in the old-used and traditional ways of teaching grammatical items in high school classes. If the pupils are engaged in the process of learning more actively and bring into practice the highlyemphasized, but less utilized notion of learning by cooperation and interaction, then both teaching and learning are facilitated. If teachers employ certain strategies to engage students in their peers' learning and indicate that they can have helpful roles in this process, they will not only be promoted in better and deeper learning but also they will find a very good feeling towards their learning context. Of course in these kinds of classes the teacher will feel more relaxed to think about other aspects of her students and bring more complex and up-to-date methods that can facilitate processes of learning and teaching. In addition, since teaching in the domain of the ZPD asks for taking into account some neglected areas of language teaching and learning in high schools, a noticeable growth in these areas might show up. In fact, in the domain of the ZPD, every feature in classroom context will find more effective role, the role which is almost neglected.

The present research is an attempt to examine whether teaching adverbs, specifically adverbs of time, manner place, based on the ZPD of the learners can produce better results in students' learning or not. In fact, this study is an attempt to compare students' learning of adverbs both in the domain of ZPD and out of it to conclude the role of ZPD in enhancing the learning of English adverbs by high school learners. Moreover, error correction is another important challenge in the classroom context that teachers and students face, so it is noticed, while teaching in the students' ZPD, which kind of assistance can help them more in correcting errors, random or negotiated, i.e., organized. It is more favorable to know how much attention to the ZPD can lead to a more stable and deeper long term learning of adverbs, too.

The present study investigates the role of ZPD in learning English adverbs by Iranian high school learners and addresses the following questions:

1- Does teaching adverbs within students' ZPD lead to a better learning of adverbs?

2- Can corrective feedback provided within learners' ZPD improve their knowledge of adverbs as opposed to feedback provided randomly and irrespective of the learners' ZPD?

3- Does teaching based on students' ZPD improve students' retention of learned adverbs?

\section{METHOD}

\section{A. Participants}

The participants were three classes of female students who had newly entered in grade one of high school. They will be randomly divided into three groups, i.e., a control group and two experimental groups. Each group consists of 25 to 30 students. These students will be chosen among at least 120 students. In order to be sure that the three groups are equally proficient, after choosing the groups, a pretest, devised according to the students' previous knowledge, was administered. Then, the mean score of the three groups were compared. This pretest both helped with the initial homogeneity and final comparison.

\section{B. Instruments}

The materials used in the present study include the grammatical points of lesson five adverbs of English Book One at high school. In order to examine the effect of ZPD something which is slightly above students' level of ability must be taught (Lave, 1988). Since adverbs are presented in students' official textbook, and nearly all students are unfamiliar with them, it is expected to be relevant to this study. In lesson five of English Book One, adverbs are presented in details. So the grammatical structures of this lesson, including adverbs and their rules, were taught to the three groups 
during four weeks. Each week consisted of two sessions: a 90- minute-session and a 45-minute one. It is worth noting that in order to comply with the educational system the instruction was limited just to those adverbs presented in the book. A 30-item-test was devised according to the adverbs covered in the students' textbook. There were 10 four-option multiple-choice items, 5 items which asked for constructing an adverb by the use of the verbs given in parentheses, 10 scrambled sentences to be unscrambled to test the position of adverbs in sentences, and 5 questions to be answered by using the adverbs given in parentheses in this test. This layout was what the students were already familiar with and the examination board of the ministry of education confirmed.

\section{Treatment}

While adverbs are taught to the control group based on the traditional ways of teaching including providing the students with explicit explanation of the rules, doing drills and exercises in the book. Teaching adverbs within the realm of the students' ZPD will be directed to the two experiential groups. In those cases, the teacher's role is that of a facilitator, or a collaborator. The students work in groups. Social interaction among the group members and between the teacher and the students is emphasized and the teacher works as a mediator. Assistance is given whenever necessary. To be more precise, each group received the followings:

1- The control group received explicit instruction, a traditional grammar lecture followed by translation exercises. The rules were taught deductively. The learners' native language was used without any limitation. Students were asked to do the exercises individually and error correction took place on the spot by the teacher. Students were also required to find the adverbs from the reading text in their textbook and write them down in a table in each session.

2- The two experimental groups received the treatment. Both groups wee engaged in the same treatment except for the error correction section (to be explained later in this paper). After a brief explanation of adverbs by the teacher in English, they dealt with doing tasks in reading and writing phases. In the reading phase, students read the reading text in their textbook. They were asked to find the intended adverbs and write them down in their notebooks in a table while they provided the missing parts.

3- As said above, another treatment was error correction. One experimental group received corrective feedback within its ZPD and the other experimental group received corrective feedback randomly and irrelevant of its ZPD (hereafter the non-ZPD error correction group).

\section{Procedures}

The present study has been done in real classroom situations exactly similar to what really happens in many high schools in Iran. So, the three groups will attend their classes two times, each taking three hours. The treatment lasts for four weeks based on the curriculum.

The adverbs were presented to all the three groups in three separate classes. As said earlier the two experimental groups worked within the ZPD. The students were exposed to situations or tasks and the teacher only gave support whenever necessary. The support was implicit as much as possible while leaving the students to discover the rules and the correct responses to questions by themselves. As students improved in each phase, the scaffolding strategies were withdrawn or faded out little by little.

One of the techniques for the two experimental groups was ten written sentences each containing one mistake in the adverb and the students were supposed to read and correct the mistakes. This approach was merely employed during the teaching phase. Therefore, in certain cases, the teachers provided help and support in accomplishing this task. However, for the ZPD error correction group, beginning from zero level and grew up little by little where and when necessary. But for the non-ZPD error correction group the teacher offered help randomly.

The 30-item test devised according to the content of the textbook used in the present study was administered two times, once after four weeks of instruction and once after six weeks. The purpose of the second administration was to see how much of the adverbs the students could recall if they had learned them within their ZPD.

\section{E. Results}

As stated earlier, after four weeks of instruction the 30-items test was administered to all the three groups. It is worth noting that all the scores of the students were taken within the range of 0 to 20 . Table 1 shows the statistics for the three groups after administration of this test

TABLE 1

DESCRIPTIVE STATISTICS OF THE SCORES OBTAINED BY ALL LEARNERS IN THE FIRST ADMINISTRATION OF THE TEST
\begin{tabular}{|l|l|l|}
\hline Groups & Mean & SD \\
\hline The Control Group & 14.07 & 3.21 \\
\hline The ZPD Error Correction Experimental Group & 17.07 & 2.98 \\
\hline The Non-ZPD Error Correction Experimental Group & 16.60 & 2.72 \\
\hline The Two Experimental Groups & 17.07 & 2.98 \\
\hline
\end{tabular}

It can be seen in the table above that the mean score of the control group is less than that of each of the experimental groups. Moreover, the table shows that the ZPD experimental group performed better than Non-ZPD experimental group. The result of the t-test indicated that the difference between the performance of the control group and that of the both experimental groups was significant (Table 2). 
TABLE 2

RESULTS OF THE COMPARISON AMONG THE PERFORMANCES OF THE GROUPS IN THE FIRST ADMINISTRATION OF THE TEST

\begin{tabular}{|c|c|c|c|c|c|c|c|}
\hline Groups & Mean & SD & Standard Error Mean & Sig & Sig(t-tailed) & $\mathrm{t}$ & df \\
\hline The Control Group & 14.07 & 3.21 & \multirow{2}{*}{0.78} & \multirow{2}{*}{0.59} & \multirow{2}{*}{0.001} & \multirow{2}{*}{-3.82} & \multirow{2}{*}{84} \\
\hline Both Experimental Groups & 17.07 & 2.98 & & & & & \\
\hline
\end{tabular}

Moreover, the comparison between the scores obtained by the two experimental groups, i.e., ZPD experimental group and Non-ZPD experimental group, reveals that they performed very closely to each other in this test and the difference between them is not significant (Table 3).

TABLE 3

RESULTS OF THE COMPARISON BETWEEN THE PERFORMANCES OF THE EXPERIMENTAL GROUPS IN THE FIRST ADMINISTRATION OF THE TEST

\begin{tabular}{|l|c|c|l|l|l|l|}
\hline Groups & Mean & SD & Sig & Sig(2-tailed) & t & df \\
\cline { 1 - 6 } The ZPD Error Correction Experimental & 17.07 & 2.98 & \multirow{2}{*}{0.41} & \multirow{2}{*}{0.57} & \multirow{2}{*}{0.56} & \multirow{2}{*}{54} \\
\hline The Non-ZPD Error Correction Experimental & 16.60 & 2.72 & & & & \\
\hline
\end{tabular}

In order to see how much students could recall adverbs when they had learned them based on their ZPDs, they took the same post-test six weeks after the first administration of the test. In this way, a comparison was done between the groups in the two administrations of the test. Table 4 shows the statistics regarding the performance of the students in the second administration.

TABLE 4

DESCRIPTIVE STATISTICS OF THE SCORES OBTAINED BY ALL LEARNERS IN THE SECOND ADMINISTRATION OF THE TEST

\begin{tabular}{|l|l|l|}
\hline Groups & Mean & SD \\
\hline The Control Group & 10.80 & 3.37 \\
\hline The ZPD Error Correction Experimental Group & 15.16 & 2.32 \\
\hline The Non-ZPD Error Correction Experimental Group & 14.71 & 2.74 \\
\hline The Two Experimental Groups & 14.87 & 2.54 \\
\hline
\end{tabular}

As table 4.4 shows, the students in the experimental groups obtained higher scores in the second administration of the test than the control group. Moreover, there was a slight decrease in the means of the groups compared with the first administration of the test. This might have happened due to the relative failure of retention in all groups. Results of a ttest revealed that the difference between the performances of the control group and that of the experimental groups was significant (Table 5).

TABLE 5

RESULTS OF THE COMPARISON AMONG THE PERFORMANCES OF THE GROUPS IN THE SECOND ADMINISTRATION OF THE TEST

\begin{tabular}{|l|l|l|l|l|l|l|l|}
\hline Groups & Mean & SD & Sig & Sig(2-tailed) & T & df \\
\cline { 1 - 3 } The Control Group & 10.80 & 3.37 & \multirow{2}{*}{0.52} & \multirow{2}{*}{0.0001} & -5.31 & \multirow{2}{*}{54} \\
\hline Both the Experimental Groups & 14.87 & 2.54 & & & \\
\hline
\end{tabular}

\section{CONCLUSIONS AND DisCUSSIONS}

The present study aimed at finding out whether or not teaching English adverbs within learners' ZPD would lead to better learning adverbs and longer stability of them. To this goal, three research questions were posed. The first question asked whether teaching adverbs in students' ZPD would lead to a better learning of adverbs. By analyzing the results reported in table 1, it can be understood that it does make a significant difference to teach based of learners' ZPD. It was confirmed that those students who received the treatment did much better than those who did not. Since they were taught by applying and/or activating their ZPD, they could internalize adverbs better and deeper and consequently could obtain higher scores in the test.

The second question, however, dealt with application of corrective feedback provided within learners' ZPD as well as the application of corrective feedback irrespective of the learners' ZPD could improve learners' knowledge of adverbs. The results showed that the students in the ZPD error correction experimental group obtained higher scores than those in the Non-ZPD error correction experimental group. However, the difference between the two groups was shown to be insignificant.

The third research question asked whether the students' retention differs when they are taught within their ZPD. In fact, after six weeks of administering the first post-test, the same test was administered again to analyze the results. It was shown that the experimental groups did much better than the control group. Another t-test was conducted to compare the experimental groups' performances against that of the control group. As indicated in table 5, the observed $t$ is 5.31 which is higher than the critical value of $t=2.00$. So, it can be said with some degree of certainty that teaching within learners' ZPD matters and leads to better retention of the materials taught.

It was shown in the present study that the learners learn better and deeper if they are taught language components, e.g., adverbs, based on their ZPD. When the class atmosphere is in a cooperative and supportive mood and the learners themselves take the responsibility for accomplishing the learning task, learning is enhanced. On the other hand, it does 
not seem that the teacher needs to explain everything in details to the learners. She can only give assistance, if needed, of course, beyond the learners' ZPD and this support gradually decreases as the learners' ability is enhanced. Also, the study indicated that giving students support based on their ZPDs to correct grammatical errors has a minor role in learning grammatical points. Moreover, when learners' ZPD is taken into account, long term retention is facilitated.

The findings of the present study are to a large extent in line with the studies conducted by Portes and Zady (1994), Gokhale (1995) and Torres (1996) as they also came to the conclusion that teaching grammatical issues within learners' ZPD can enhance learning well. Gokhale (1995) also concluded that collaborative learning is more productive than individual learning. Portes and Zady (1994) also found that students are more successful in problem solving when they work cooperatively. Another reason for students' improvement might lie in their feeling of being autonomous and selfdependent. This has also been shown to create a more convenient atmosphere for better learning and longer retention.

\section{REFERENCES}

[1] Beheshti, J., Bowler, L., Large, A., \& Nessest, V. (2000). Children and adults working together in the Zone of Proximal Development: A theory for user-centered design. McGill University.

[2] Brown, H. D. (2001). Teaching by principles: An interactive approach to language pedagogy. NY: Addison Welsey Longman.

[3] Celce-Murcia, M,. (1991). Teaching English as a second or foreign language. Heinle \& Heinle P. 244.

[4] Dillenbourg P. (1999). What do you mean by collaborative learning?. In P. Dillenbourg (Ed) Collaborative-learning: Cognitive and Computational Approaches. (pp.1-19). Oxford: Elsevier

[5] Fortenberry, G. (1998). Kagan cooperative learning. http://www.woodrow.org/teachers/bi/1998/presentations/fortenberry/ (accessed 20/3/2009).

[6] Gass, S. (1997). Input, interaction, and second language learner. Mahwah, NJ: Lawrence Erlbaum Associates.

[7] Gokhale, A,. (1995). Collaborative Learning Enhances Critical Thinking. Journal of Technology Education. 7(1), 22-30.

[8] Lantolf, J. P. and Thorne, S. L. (2006). Sociocultural theory and the genesis of second language development. Oxford: Oxford University Press.

[9] Mayer, R. E. (2003). Learning and instruction. Upper Saddle River, NJ: Prentice Hall.

[10] Nassaji, H. \& Swain, M. (1997). A Vygotskian perspective on corrective feedback in L2: The effect of random versus negotiated help on the learning of English articles. Language Awareness 9(1), 34-51.

[11] Portes, P. R., \& Zady, M. F. (1994). Assistance in Science-Related Parent Child Interaction. Paper presented at the American Educational Research Association annual meeting, New Orleans,

[12] LA. Richards, Jack C. \& Rodgers, Theodore S. (2001). Approaches and Methods in language Teaching (2 ${ }^{\text {nd }}$ Edition). Cambridge: Cambridge University Press.

[13] Scheeler, M. C., Ruhl, K. L., \& MacAfee, J. (2004). Providing performance feedback to teachers: A review. Teacher Education and Special Education. 27(3), 59-70.

[14] Schutz, R. (2004). Vygotsky and language acquisition. http://www.sk.com.br/sk-vygot.html (accessed 12/4/2010).

[15] Scott, E. (2008). Corrective feedback in the language classroom: How to best point out language mistakes. http://www.suite101.com/content/corrective-feedback-in-the-language-classroom-a67114 (accessed 25/11/2009).

[16] Torres, M. N. (1996). Cognitive individualism: An impediment to teachers' collaborative intellectual work. Paper presented at the Annual Meeting of the American Educational Research Association (New York, NY, April 8-12, 1996).

[17] Wertsch, J. V., \& Stone, C. A. (1985). The concept of intemalkation in Vygotsky's account of the genesis of higher mental functions. In J. V. Wertsch (Ed.), Culture, communication, and cognition: Vygotskian perspectives (pp. 162-179). New York: Cambridge University Press.

[18] Widdowson, G. H. (1990). Aspects of Language Teaching. New York: Oxford University Press.

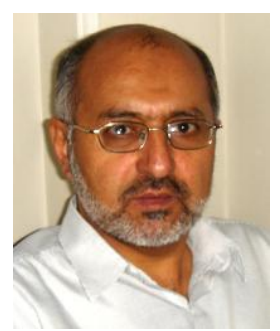

Abbas Ali Rezaee was born in Tehran, IR Iran, in 1956. He finished his MA in Teaching English as a Foreign Language (TEFL) in Tabiat Modarres University, Tehran, in 1989 and obtained his PhD in Applied Linguistics from the University of Exeter, England, in 2001.

He is currently a member of academic staff at the Department of English Language and Literature, Faculty of Foreign Languages and Literatures, University of Tehran. He has published many articles in national and international journals. He has taught specialized courses at BA, MA and PhD levels and has also supervised a large number of MA theses and $\mathrm{PhD}$ dissertation in language teaching and testing. His main research interests are Language Teaching, Language Testing, Discourse Analysis, ESP, and CALL.

Dr. Rezaee is a member of the Teachers of English Language and Literature Society in Iran (TELLSI). He is the reviewer for a number of domestic and international journals.

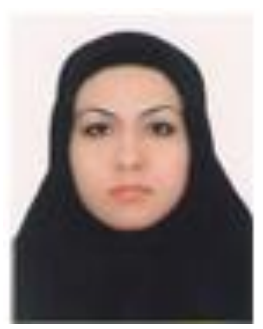

Zeinab Azizi was born in 1982 in Borujerd, Lorestan Province, IR Iran. She finished her BA in English language and Literature in Islamic Azad University, Borujerd, Iran and obtained her Masters in Teaching English as a Foreign Language (TEFL) from the University of Tehran, Iran in 2009.

She is currently teaching at the university level in Borujerd. She is currently compiling a course-book on reading comprehension in English to be published for university students.

Miss Azizi is a keen researcher in the areas of language teaching and learning. Her main research interests are teaching English grammar within the framework of Zone of Proximal Development and corrective feedback among university language learners. 